\title{
Delayed Proximal Flow Diverting Stent Migration in a Ruptured Intracranial Aneurysm: A Case Report
}

\author{
Wittawat Takong, $\mathrm{MD}^{1}$, Chai Kobkitsuksakul, $\mathrm{MD}^{2}$ \\ ${ }^{1}$ Neuroscience Center, Bangkok Pattaya Hospital, Chonburi, Thailand \\ ${ }^{2}$ Division of Interventional Neuroradiology, Faculty of Medicine, Department of Diagnostic and Therapeutic Radiology, Ramathibodi Hospital, \\ Mahidol University, Bangkok, Thailand
}

\begin{abstract}
A flow diverter can be used to treat a ruptured aneurysm, especially during complicated cases for endovascular or open microsurgical procedures. However, some complications have been reported such as occlusion of side branches or perforating arteries, stent migration or improper stent position, re-rupture of the aneurysm, and in-stent thrombosis. A 38-year-old man diagnosed with a ruptured left supraclinoid aneurysm was treated with a Pipeline embolization device. Despite adequate stent coverage of the aneurysmal neck, delayed proximal migration was seen in follow-up imaging. To our knowledge, proximal migration of the stent mostly happens intraoperatively due to an undersized stent or excessive stretching. We report a case of delayed proximal flow diverter stent migration.
\end{abstract}

Key Words: Flow diverter; Stent migration; Ruptured aneurysm

\section{INTRODUCTION}

Endovascular treatment has become an option for treating a ruptured intracranial aneurysm. Transarterial coil embolization of a ruptured aneurysm is associated with excellent clinical outcomes.' However, broad-necked saccular or fusiform aneurysms are difficult to treat with coil embolization, even with assisted techniques such as stent or balloon-assisted coil embolization. Several reports have shown that a flow diverter can be used to treat a ruptured aneurysm, especially during complicated cases for endovascular or open microsurgical procedures. ${ }^{2}$ Flow diverter deployment in a ruptured intracranial aneurysm is also associated with a high rate of aneurysmal occlusion and good clinical outcomes in selected patients. ${ }^{2}$ The overall complication rate of flow diverter deployment is about $17 \%$ with stent migration or about $5.8 \%$ with poor positioning. ${ }^{3}$ Proximal stent migration typically occurs intraoperatively due to flow diverter foreshortening from implantation of an undersized device resulting in aneurysm recurrence. In contrast, the incidence of distal stent migration has been reported to be 5.9\%.3,4 We report a case of stent migration in a delayed setting from follow-up computed tomography (CT) angiography and a cerebral angiogram.

\section{Correspondence to:}

Wittawat Takong, MD

Neuroscience Center, Bangkok Pattaya Hospital, 301 Sukhumvit Road, Pattaya, Chonburi 20150, Thailand Tel: +66-8-9622-7987

Fax: +66-38259990

E-mail:morwittta@gmail.com

Received: May 28, 2020

Revised: September 1, 2020

Accepted: September 13, 2020

Copyright $\odot 2020$ Korean Society of Interventional Neuroradiology

This is an Open Access article distributed under the terms of the Creative Commons Attribution Non-Commercial License (http://creativecommons.org/licenses/by-nc/4.0) which permits unrestricted non-commercial use, distribution, and reproduction in any medium, provided the original work is properly cited.

pISSN 2093-9043 eISSN 2233-6273 


\section{CASE REPORT}

A 38-year-old man presented at our hospital with a headache. His CT and CT angiography scans of the brain showed acute subarachnoid hemorrhage at the basal cistern and left Sylvian fissure, as well as a possible tiny aneurysm at the left supraclinoid internal carotid artery. Cerebral angiogram demonstrated a small blister aneurysm at the medial aspect of the left supraclinoid internal carotid artery, with a size of $1.4 \times 1.3 \times 1.3 \mathrm{~mm}$ (width $\times$ height $\times$ neck) (Fig. 1A). The diameter of the parent artery distal to the aneurysm was $4.5 \mathrm{~mm}$ and $3.6 \mathrm{~mm}$ proximal to the aneurysm. The treatment plan between surgical clipping and endovascular treatment was broadly discussed. Our neurovascular team chose the endovascular option, which was endovascular flow diversion treatment using a 4.5×16 mm Pipeline embolization device (PED) (ev3 Neurovascular, Inc., Irvine, CA, USA). The stent was deployed to cover the aneurysm due to challenges in clipping and coiling. Before placing the stent, dual antiplatelet drugs were administered orally via a nasogastric tube after crushing $300 \mathrm{mg}$ clopidogrel and $325 \mathrm{mg}$ aspirin. The Pipeline shield flow diverting stent was placed to cover the left supraclinoid blister aneurysm. Unfortunately, there was an intra-procedural flow diverting stent foreshortening during stent deployment. At that time, we used the largest available suitable flow diverter as well as an unsheathing and pushing technique to minimize the "accordion" effect. However, the stent still covered the aneurysm neck, with the distal end of the stent located at $3 \mathrm{~mm}$ distal to the neck (Fig. 1B), which demonstrated contrast stagnation within the aneurysm during contrast injection. Initial stent deploy- ment was not appropriate because most of it was deployed proximally to the aneurysm. No postoperative complications occurred, and the patient was doing well. Four weeks later, follow up CT angiography of the brain showed proximal stent migration. There was only 50\% aneurysmal neck coverage. A slightly increased size of the aneurysm was detected as well. We planned to deploy a second flow diverting stent. The platelet aggregation test showed 12.8\% with adenosine diphosphate $10 \mu \mathrm{mol}$ (control 72.2\%) and 13.6\% with Arachidonic acid $500 \mu \mathrm{g} / \mathrm{mL}$ (control 70.4\%). Two weeks later, repeated cerebral angiograms demonstrated further increased size of the aneurysm to $5.3 \times 5.1 \mathrm{~mm}$ (widthxheight) with a narrowing aneurysmal neck of $2.2 \mathrm{~mm}$ (Fig. 1C). The images also showed further foreshortening of the stent from 22.1 $\mathrm{mm}$ to $19.8 \mathrm{~mm}$ in length. The procedure was switched from the second flow diverter to intrasaccular coiling (Fig. 1D). The procedure went well and the patient was uneventfully discharged.

\section{DISCUSSION}

Flow diverter deployment for a ruptured aneurysm has shown a high rate of angiographic occlusion and good clinical outcomes. ${ }^{2}$ However, complications of the treatment have been reported, such as occlusion of side branches or perforating arteries, stent migration or improper stent position, re-rupture of the aneurysm, and in-stent thrombosis. ${ }^{3}$ The complications have been reported in the delayed phase, so clinical and angiographic follow-up is crucial. In this particular case, we found stent migration at 4 weeks using
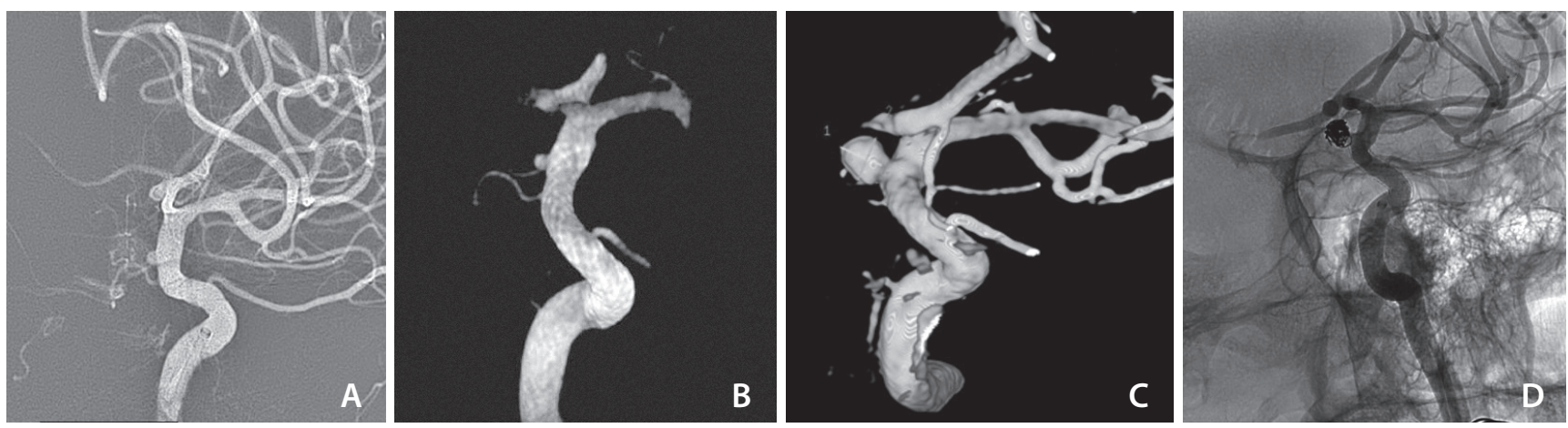

Fig. 1. Thirty-eight years old male with a ruptured aneurysm. (A) Initial angiography showed a tiny wide-neck aneurysm on dorsal wall of internal carotid artery. (B) 3D angiogram immediately after placement of Pipeline embolization device (PED) demonstrated stent covering the neck of aneurysm (although most of stent was placed proximal to the aneurysm). (C) Follow-up angiography at 6 weeks later showed a growing aneurysm with narrow neck. (D) Control angiography after coil embolization demonstrated nearly complete obliteration of the aneurysm. The distal part of PED partially covered narrow neck of aneurysm. 
follow-up CT angiography, which showed only 50\% stent coverage of the aneurysmal neck. A cerebral angiogram confirmed stent migration and a rapidly growing aneurysm. Several reports showed treatment of delayed stent migration with second flow diverter deployment, coiling, or stent-assisted coiling to occlude the aneurysm. ${ }^{5}$

Prevention of stent migration is better than treating stenting migration. There are many factors affecting stent migration. We divided these factors into stent factors, technical factors, and lesion factors.

Regarding stent factors, a PED is particularly vulnerable to spontaneous migration due to its low porosity and closedcell design, which facilitates the transmission of a force exerted at one end of the device to the other end. ${ }^{6,7}$ The incidence of PED migration is quite similar to Enterprise stents (Cordis, Miami Lake, FL, USA), whereas it has never happened with Neuroform stents (Boston Scientific, Natick, MA, USA). ${ }^{8}$ The Neuroform stent has an open-cell or half-open-cell design, causing separate fixation of each segment liked the flared end of an Enterprise stent to enhance the apposition of the stent to the wall. A force used at one end will not be directly transmitted to the other end.

Regarding lesion factors, when the distal vessel diameter is too small compared with the proximal vessel diameter, the distal end of the stent cannot be fully flared to enhance the apposition of the stent, and a squeezing force can occur. This phenomenon is called the "watermelon seed effect" $1,7,9$

Regarding technical factors, the size of the stent is also essential because it can be foreshortened when using an undersized stent or elongated when using an oversized stent. To avoid the problem, a $0.25-0.5 \mathrm{~mm}$ diameter larger than the distal parent vessel diameter is generally recommended. ${ }^{3}$ Also, excessive dragging and stretching of the stent can cause stent migration and shortening due to "watermelon seed" or "accordion" effects of the device.

In this case, the possible mechanisms of stent migration could be due to dragging and stretching of the stent due to many curves of the carotid siphon stent placement, further foreshortening due to shortening of the stent in follow-up digital subtraction angiography, a diameter difference between the distal and proximal parent artery, or an inappropriate location of the initial stent deployment due to stent covering only $3 \mathrm{~mm}$ distal to the aneurysm.

One limitation of this case report is there was no follow-up vascular study after retreatment to evaluate the result of putting coils in the blister aneurysm. A 3- to 6-month follow-up angiography should be performed.

Delayed stent migration can occur following flow diverter stent deployment due to multiple factors. A follow-up vascular study is very important to detect stent migration and its consequences.

\section{Fund}

None.

\section{Ethics Statement}

Ethics approval was obtained from the local institutional review board.

\section{Conflicts of Interest}

The authors have no conflicts to disclose.

\section{Author Contributions}

Concept and design: WT. Writing the article: WT. Critical revision of the article: CK. Final approval of the article: WT and CK. Overall responsibility: WT.

\section{ORCID}

Wittawat Takong: https://orcid.org/0000-0002-2492-8378

Chai Kobkitsuksakul: https://orcid.org/0000-0001-8873-4591

\section{REFERENCES}

1. Molyneux AJ, Kerr RS, Yu LM, Clarke M, Sneade M, Yarnold JA, et al.; International Subarachnoid Aneurysm Trial (ISAT) Collaborative Group. International subarachnoid aneurysm trial (ISAT) of neurosurgical clipping versus endovascular coiling in 2143 patients with ruptured intracranial aneurysms: a randomised comparison of effects on survival, dependency, seizures, rebleeding, subgroups, and aneurysm occlusion. Lancet 2005;366:809-817

2. Madaelil TP, Moran CJ, Cross DT 3rd, Kansagra AP. Flow diversion in ruptured intracranial aneurysms: a meta-analysis. AJNR Am J Neuroradiol 2017;38:590-595

3. Zhou G, Su M, Yin YL, Li MH. Complications associated with the use of flow-diverting devices for cerebral aneurysms: a systematic review and meta-analysis. Neurosurg Focus 2017;42:E17

4. Dornbos D 3rd, Powers CJ. Acute distal migration of a flow diverting stent. J Clin Neurosci 2017:44:223-225

5. Tsai YH, Wong HF, Hsu SW. Endovascular management of spontaneous delayed migration of the flow-diverter stent. J Neuroradiol 2020;47:38-45 
Takong W et al. Delayed Flow Diverting Stent Migration

6. Chalouhi N, Tjoumakaris SI, Gonzalez LF, Hasan D, Pema PJ, Gould G, et al. Spontaneous delayed migration/shortening of the pipeline embolization device: report of 5 cases. AJNR Am $J$ Neuroradio/ 2013;34:2326-2330

7. Lavine SD, Meyers PM, Connolly ES, Solomon RS. Spontaneous delayed proximal migration of enterprise stent after staged treatment of wide-necked basilar aneurysm: technical case report. Neurosurgery 2009;64:E1012
8. Gao B, Malek AM. Possible mechanisms for delayed migration of the closed cell--designed enterprise stent when used in the adjunctive treatment of a basilar artery aneurysm. AJNR Am J Neuroradiol 2010;31:E85-E86

9. Badruddin A, Lazzaro MA, Taqi MA, Zaidat OO. Downward migration of carotid stent on 8 months follow-up imaging: possible stent "watermelon- seeding" effect. J Neuroimaging 2011;21:395-398 